\title{
Pemanfaatan Pompa Centrifugal Untuk Mengoptimalkan Lahan Mati Menjadi Lahan Produktif
}

\section{Armila \\ Teknik Mesin/Fakultas Teknik/ Universitas Muhammadiyah Sumatera Barat Email:Kimmylala74@gmail.com}

\begin{abstract}
Abstrak: Indonesia merupakan negara agraris yang menjadikan sektor pertanian sebagai penopang perekonomian negara. Mekanisasi dalam pertanian dalam arti luas bertujuan untuk meningkatkan produktifitas tenaga kerja, meningkatkan produktifitas lahan, dan menurunkan ongkos produksi. Penggunaan alat dan mesin pada proses produksi dimaksudkan untuk meningkatkan efesiensi, efektifitas, produktifitas, kualitas hasil, dan mengurangi beban kerja petani. Keterbatasan sumber air menyebabkan banyak lahan dibiarkan tidak produktif, Indonesia beriklim tropis khususnya Sumatera Barat, dimana sepanjang tahun hujan selalu turun, akan tetapi hal ini tidak dijadikan sebagai sumberdaya oleh petani untuk ditampung dan digunakan untuk menyiram lahan. Teknologi Pompa Sentrifugal merupakan teknologi yang sederhana yang mampu memindahkan air dari kolam penampungan ke lahan, sehingga lahan yang tidak produktif dapat dipakai untuk kegiatan pertanian, yang menghasilkan produk pertanian yang baik dan berkualiatas, sehingga dapat dijadikan sebagai sebuah kegiatan yang sangat bernilai ekonomis. Mekanisasi menghadirkan petani yang modern dengan produktivitas dan kualiatas yang tinggi dan terukur.
\end{abstract}

Kata kunci: Pompa sentrifugal, Air, Lahan, Mekanisasi, produktif

\begin{abstract}
Abstrack:Indonesia is an agriculture country, agriculture sector was supporting economic, because large of people works as a farmer. Mechanised agriculture is process of using agricultural machinery to mechanised the work of agriculture, greatly increasing farm worker productivity. In modern times, powered machinery has replace many farm job formerly carried out by manual labour or working animals. Water resources are mainly reason why agriculture is "stop". Indonesia is tropicall country specially West Sumatera is hight rainfall all single year. Its resources intake into pool. centrifugal pumps commonly used for irrigation fall into the following categories based on the design of the pump to flow water running out from the pool into the land. So unprospect land becomes productive and agriculture process as an economic highly process. Mechanization determined modern farmer which hight productivity and quality, and in the future farmer is chooise and prestisius job.
\end{abstract}

Keyword: Centrifugal Pumps, water, land, mechanization, productive 


\section{PENDAHULUAN}

\subsection{Latar Belakang}

Dilatarbelakangi dari kuliah umum yang kami adakan yang mengusung tema "Mekanisasi Dalam Pertanian". Dalam kuliah umum ini pemateri Adalah seorang praktisi pertanian lulusan dari Jepang, yang telah melakukan kegiatan Pertanian menggunakan Teknologi Permesinan sebagai perangkat utama yang harus ada dalam kegiatan pertanian. Mulai dari penggunaan traktor roda empat, roda dua, bermacammacam bajak (rotary, tunggal dll) untuk pengolahan tanah. Untuk penyiraman lahan pemateri menganjurkan menggunakan pompa karena lebih dari 90\% lahan tidak produktif/mati hanya karena tidak adanya sumber air. Pemaparan panjang lebar betapa besarnya peran teknologi permesinan dalam kegiatan pertanian membuat mahasiswa sadar akan potensi diri mereka. Dimana sebagian besar mereka adalah keluarga petani yang sumber penghidupan mereka sangat bergantung pada hasil pertanian dan perkebunan. Setelah selesai kulia umum mahasiswa penasaran akan teknologi permesinan untuk pertanian, mahasiswa meminta supaya mereka bisa melakukan praktek tentang pemaparan materi yang mereka terima, kami mencoba mengupayakan untuk mendapatkan kesempatan menerapkan teknologi permesinan sederhana dalam proses pertanian. Dari hasil diskusi kami dapat memanfaatkan lahan $1 \mathrm{Ha}$, dimana lahan ini adalah lahan mati karena tidak adanya sumber air, dalam hal ini kami ditantang untuk dapat menjadikan lahan ini menjadi lahan subur dengan menggunakan pompa untuk menyiram lahan dengan menampung air hujan sebagai sumber air. pemateri memberikan pengetahuan tentang tanaman prospek dan produktif untuk ditanam, dengan pengolahan sederhana dan tidak membutuhkan perawatan yang rumit, artinya tidak terlalu menyita waktu.

Kami diberikan lokasi di Daerah Baso seluas Kurang Lebih $1 \mathrm{Ha}$.

Di Daerah tersebut sumber air banyak tetapi terletak sangat jauh dari lahan, dimana masyarakat hanya sedikit yang memanfaatkan lahan, lahan dibiarkan terbengkalai karena alasan tidak ada air untuk menyiram tanaman.

Adapun sebahagian petani menggunakan ember untuk mengangkut air dari sumber yang cukup jauh kurang lebih $1.5 \mathrm{~km}$ dari lokasi lahan diangkut menggunakan beca motor untuk menyiram lahan pertanian, tentu hal ini sulit dan melelahkan, dan jika diberikan kepada orang lain/buruh tani maka akan mahal, dan tidak akan mampu dicapai keuntungan setelah panen.

Rencana awal kami akan melakukan penyiraman dengan sistem Sprinkle tapi karena terkendala dana kami hanya menggunakan pompa sentrifugal dengan membuat kolam air hujan sebagai sumber air untuk menyiram lahan.

\subsection{Maksud dan Tujuan}

Maksud penyiraman dengan pompa adalah memudahkan pekerjaan pengolahan lahan pertanian, didasarkan pada konsep ilmu permesinan yaitu meminimalkan pemakaian tenaga manusia.

Tujuan dari penyiraman dengan pompa adalah menjaga suplay air yang dibutuhkan tanaman tetap terjaga dengan baik sehingga kualitas tanaman sesuai dengan target yang diharapakan.

\section{TINJAUAN PUSTAKA}

\subsection{Pengertian Pompa Centrifugal}

Pompa Sentrifugal merupakan jenis pompa yang paling banyak dipakai dalam dunia kontraktor, mekanikal dan elektrikal. Pompa ini mempunyai beberapa kelebihan karena mudah mengoperasikannya, pemeliharaan tidak terlalu mahal dan pada pemakaian tidak terlalu berisik.

Pompa Sentrifugal atau centrifugal pumps adalah pompa yang mempunyai elemen utama yaitu berupa motor penggerak dengan sudu impeller yang berbutar dengan kecepatan tinggi. Prinsip kerjanya mengubah energi mekanis menjadi energi kinetis, kemudian fluida diarahkan kesaluran buang dengan memakai tekanan (energi kinetis sebagian fluida diubah menjadi energi tekanan) dengan menggunakan impeller yang berputar di dalam casing.

Casing tersebut dihubungkan dengan saluran hisap (suction) dan saluran tekan 
(discharge), untuk menjaga agar di dalam casing selalu terisi dengan cairan sehingga saluran hisap harus dilengkapi dengan katup kaki (foot valve).

Prinsip Kerjanya sangat sederhana dimana menggunakan mesin/motor untuk memindahkan cairan dari suatu tempat ketempat lain melalui suatu media perpipaan dengan cara menambahkan energi pada cairan yang dipindahkan dan berlangsung secara terus menerus. Pompa beroperasi dengan prinsip membuat perbedaan tekanan antara bagian masuk (suction) dengan bagian keluar (discharge).

Dengan kata lain, pompa berfungsi mengubah tenaga mekanis dari suatu sumber tenaga (penggerak) menjadi tenaga kinetis (kecepatan), dimana tenaga ini berguna untuk mengalirkan cairan dan mengatasi hambatan yang ada sepanjang pengaliran.

Pompa digerakkan oleh motor. Daya dari motor diberikan kepada poros pompa untuk memutar impeller yang terpasang pada poros tersebut. Zat cair yang ada didalam impeller akan ikut berputar karena dorongan sudusudu. Karena timbul gaya sentrifugal maka zat cair mengalir dari tengah impeler akan keluar melalui saluran diantara sudu-sudu dan meninggalkan impeller dengan kecepatan tinggi. Zat cair yang keluar dari impeller dengan kecepatan tinggi ini kemudian akan keluar melalui saluran yang penampangnya makin membesar (volute/difuser) sehingga terjadi perubahan dari head kecepatan menjadi head tekanan. Oleh sebab itu zat cair yang keluar dari flens pompa memiliki head total yang lebih besar.
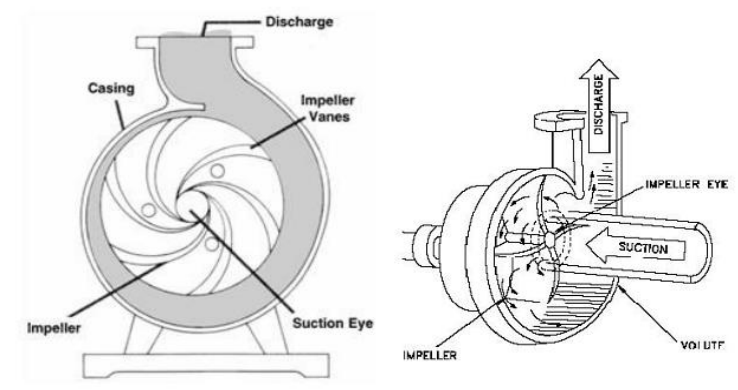

Gambar 2.

1 Mekanisme zat cair dalam pompa sentrifugal

\subsection{Klasifikasi Pompa Sentrifugal}

Pompa sentrifugal dapat diklasifikasikan berdasarkan:

1. Kapasitas:

- Kapasitasrendah< $20 \mathrm{~m} 3 / \mathrm{jam}$

- Kapasitasmenengah 20-60 m3/jam

- Kapasitastinggi> $60 \mathrm{~m} 3 / \mathrm{jam}$

2. Tekanan Discharge:

- TekananRendah< $5 \mathrm{Kg} / \mathrm{cm} 2$

- Tekananmenengah $5-50 \mathrm{Kg} / \mathrm{cm} 2$

- Tekanantinggi $>50 \mathrm{Kg} / \mathrm{cm} 2$

3. Jumlah / Susunan Impeller dan Tingkat:

Single stage: Terdiri dari satu impeller dan satu casing

- Multi stage: Terdiri dari beberapa impeller yang tersusun seri dalam satu casing.

- Multi Impeller: terdiri dari beberapa impeller yang tersusun parallel dalam satu casing.

- Multi Impeller "Multi stage": Kombinasi multi impeller dan multi stage.

4. Posisi Poros

- Poros tegak

- Poros mendatar

5. Jumlah Suction

- Single Suction

- Double Suction

6. Arah aliran keluar impeller

- Radial flow

- Axial flow

- Mixed fllow

Fungsi dan Bagian-bagian Utama Pompa Sentrifugal, Secara umum bagian-bagian utama pompa sentrifugal dapat dilihat seperti gambar berikut:

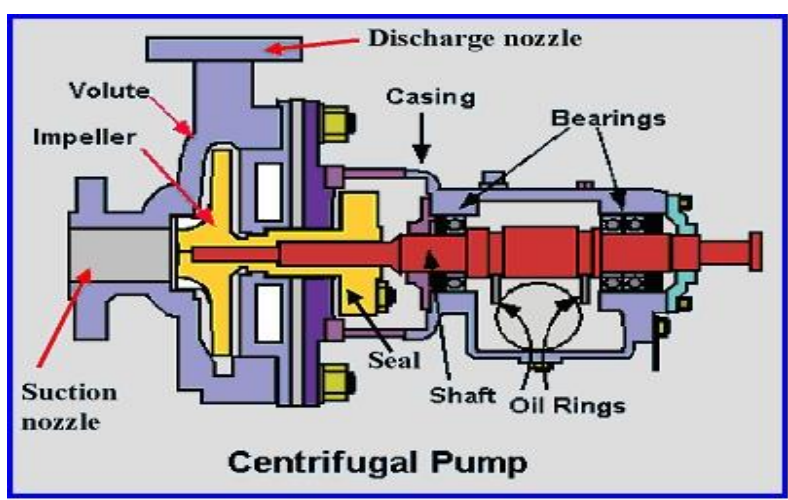

Gambar 2.2 Bagian-bagian Pompa Sentrifugal 
Penghisapan terjadi karena setelah zat cair dilemparkan oleh impeller, ruang di antara sudu-sudu menjadi turun tekanannya sehingga zat cair akan terhisap masuk.

Secara umum pompa sentrifugal tersusun atas beberapa bagian penting yaitu:

- Casing

- Impeller

- Shaft/Poros

- Bearing/Bantalan

- Kopling

- Packing \& Seal

- Sistem Lubrikasi

Bagian-bagian Pompa Sentrifugal:

Casing

Komponen utama pertama dari pompa sentrifugal adalah casing pompa. Casing pompa sentrifugal didesain berbentuk sebuah diffuser yang mengelilingi

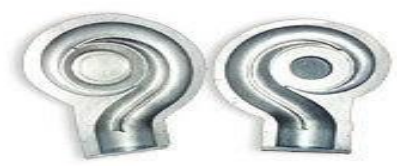

\section{Gambar 2.3 Volute Casing Pompa Sentrifugal}

impeller pompa. Diffuser ini lebih sering dikenal sebagai volute casing. Sesuai dengan fungsi diffuser, volute casing berfungsi untuk menurunkan kecepatan aliran (flow) fluida yang masuk ke dalam pompa. Menuju sisi outlet pompa, volute

casing didesain membentuk corong yang berfungsi untuk mengkonversikan energi kinetik menjadi tekanan dengan jalan menurunkan kecepatan dan menaikkan tekanan, hali ini juga membantu menyeimbangkan tekanan hidrolik pada shaft pompa.

\section{Impeller}

Impeller adalah bagian yang berputar dari pompa sentrifugal, yang berfungsi untuk mentransfer energi dari putaran motor menuju fluida yang dipompa dengan jalan mengakselerasinya dari tengah impeller ke luar sisi impeller.

Desain impeller bergantung atas kebutuhan tekanan, kecepatan aliran, serta kesesuaian dengan sistemnya. Impeller menjadi komponen yang paling utama berpengaruh terhadap performa pompa. Modifikasi desain impeller akan langsung berpengaruh terhadap bentuk kurva karakteristik pompa tersebut. Ada berbagai macam desain impeller pompa sentrifugal, antara lain tipe tertutup dan terbuka, tipe single flow, tipe mix flow, tipe radial, tipe non-clogging, tipe single stage, dan tipe multi stage.

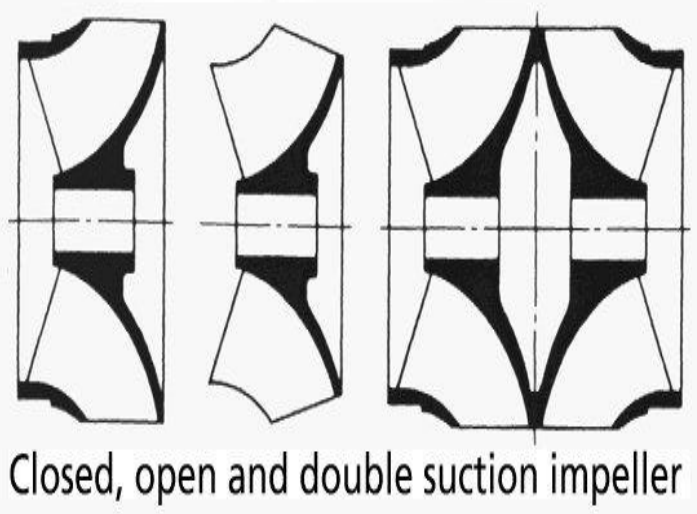

\section{Gambar 2.4 Beberapa contoh tipe impeller}

\section{Poros (Shaft)}

Poros pompa adalah bagian yang mentransmisikan putaran dari sumber gerak, seperti motor listrik, ke pompa. Yang perlu kita perhatikan adalah, pada sebuah pompa sentrifugal yang bekerja di titik efisiensi terbaiknya, maka gaya bending porosnya akan secara sempurna terdistribusikan ke seluruh bagian impeller pompa.

\section{Bearing}

Bearing pada pompa berfungsi untuk menahan (constrain) posisi rotor relatif terhadap stator sesuai dengan jenis bearing yang digunakan. Bearing yang

digunakan pada pompa yaitu berupa journal bearing yang berfungsi untuk menahan gaya berat dan gaya-gaya yang searah dengan gaya berat tersebut, serta thrust bearing yang berfungsi untuk menahan gaya aksial yang timbul pada poros pompa relatif terhadap stator pompa. 


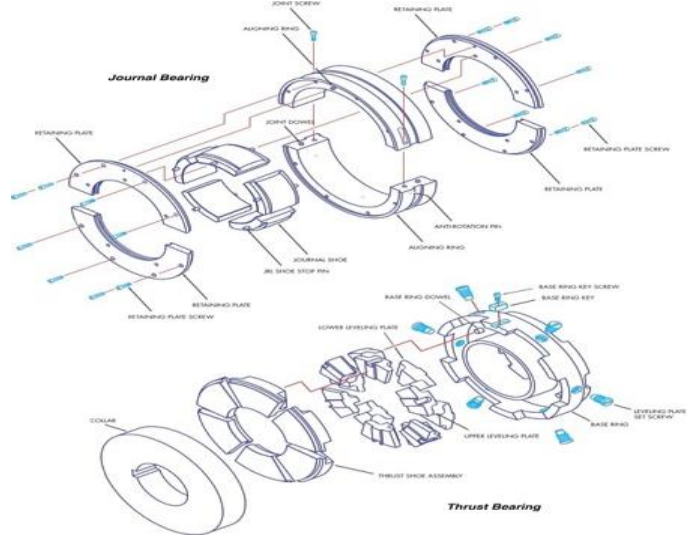

Gambar 2.5 Skema Journal dan Thrust Bearing

\section{Kopling}

Pada dasarnya kopling berfungsi untuk menghubungkan dua shaft, dimana yang satu adalah poros penggerak dan yang lainnya adalah poros yang digerakkan. Kopling yang digunakan pada pompa, bergantung dari desain sistem dan pompa itu sendiri. Macammacam kopling yang

digunakan pada pompa dapat berupa kopling rigid, kopling fleksibel, grid

coupling, gear coupling, elastrometic coupling, dan disc coupling.

\section{Sistem Packing}

Sistem packing pada pompa adalah untuk mengontrol kebocoran fluida yang mungkin terjadi pada sisi perbatasan antara bagian pompa yang berputar (poros) dengan stator. Sistem sealing yang banyak digunakan pada pompa sentrifugal adalah mechanical seal dan gland packing.

Penghisapan terjadi karena setelah zat cair dilemparkan oleh impeller, ruang di antara sudu - sudu menjadi turun tekanannya sehingga zat cair akan terhisap masuk.

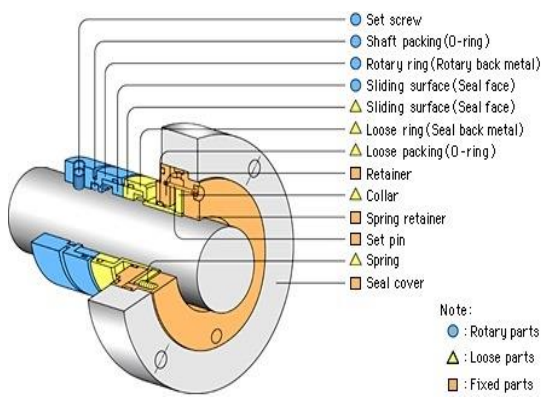

Gambar 2.6 Sistem Mechanical Seal

\section{Sistem Lubrikasi}

Sistem lubrikasi pada pompa berfungsi untuk mengurangi koefisien gesek antara dua permukaan yang bertemu sehingga bearing. Sistemnya dapat berupa lub oil atau juga tipe greas tergantung dari desain pompa itu sendiri.

\subsection{Pengertian Irigasi}

Pertanian dengan menggunakan Irigasi adalah cara maupun usaha yang dilakukan oleh manusia untuk memberikan aliran air kelahan pertanian. Fungsi utama irigasi dalam bidang pertanian ini adalah untuk mengairi lahan-lahan pertanian, seperti sawah agar mendapat pasokan air. Jadi dengan adanya irigasi, maka kebutuhan air untuk pertanian akan tercukupi. Jika lahan pertanian kekurangan air, maka untuk melakukan budidaya pertanian akan terhambat dan mengalami kendala. Hasil panen pertanian bisa saja gagal.

Ada beberapa jenis-jenis irigasi yang ada dalam bidang pertanian, tentang apa saja jenis irigasi yang ada dalam pertanian.

\subsubsection{Irigasi Permukaan}

Irigasi permukaan adalah system irigasi yang dilakukan dengan cara mengambil air langsung dari sumber air di sungai melalui bendungan maupun bangunan pengambil bebas (free intake) lalu air tersebut dialirkan secara gravitasi. Proses pengaliran air ke lahan pertanian dengan system irigasi permukaan ini yaitu melalui saluran. Ada beberapa saluran yang dikenal dalam system irigasi permukaan ini yaitu saluran primer, saluran sekunder, dan saluran tersier. Jadi karena system pengairan dilakukan secara gravitasi, maka tanah yang memiliki permukaan tinggi akan mendapatkan air lebih dulu dibanding tanah yang ada didataran rendah.

\subsubsection{Irigasi Penyemprotan}

Jenis irigasi selanjutnya adalah irigasi penyemprotan. Namanya penyemprotan jelas menggunakan alat penyemprot air atau biasa disebut dengan sprinkle. Sistem kerjanya adalah air yang disemprotkan akan tampak seperti kabut dan tanaman akan mendapatkan air dari atas.

\subsubsection{Irigasi Tradisional}


Jenis irigasi yang ini merupakan irigasi tradisional. Irigasi tradisional merupakan irigasi dengan sistem manual yaitu menggunakan ember. Pengairan air ke lahan pertanian dilakukan dengan cara mengangkut air menggunakan ember. Sistem irigasi ini sangat membutuhkan banyak tenaga dan waktu, jadi kurang efektif jika digunakan dalam pertanian.

\subsubsection{Irigasi Pompa Air}

Jenis irigasi yang terakhir adalah irigasi pompa air. Proses pengaliran air menggunakan irigasi jenis pompa air ini yaitu sumber air dialirkan dengan menggunakan pompa air, kemudian dialirkan dengan berbagai macam cara, seperti menggunakan pipa atau paralon dan selang air. Jadi sistem irigasi pompa air ini sangat efektif jika dilakukan pada musim kemarau. Karena di musim kemarau, air akan mengalami surut dan untuk mengairi lahan pertanian hanya bisa dilakukan dengan menyedot air dari sumber ke lahan pertanian dengan menggunakan pompa air.

Dalam kegiatan ini kami menggunakan pompa sentrifugal memakai selang air dan nozel, kemudian disemprotkan pada lahan yang membutuhkan.

Pemakaian pompa dilakukan karena tidak adanya sumber air disekitar lahan sehingga kita mencari cara dengan menampung air (terutama air hujan).

Berikut ini model adalah model kolam penampung air yang akan dibuat sebagai sumber air untuk lahan.

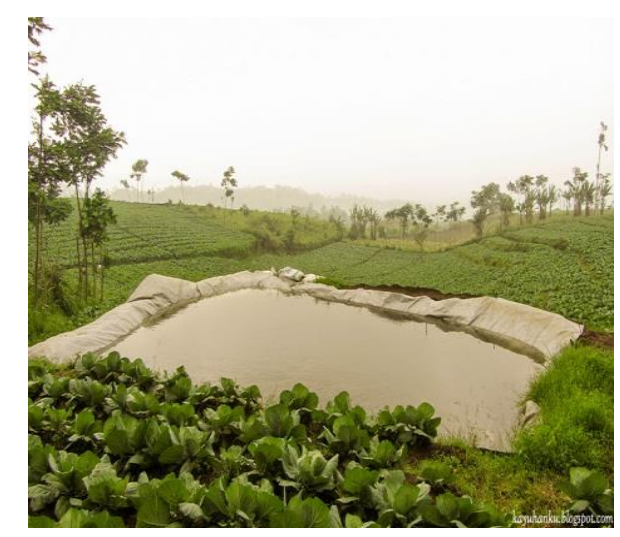

Gambar 2.7 Kolam Penampungan air hujan
METODA PENELITIAN

1.1 Diagram Alir Penelitian

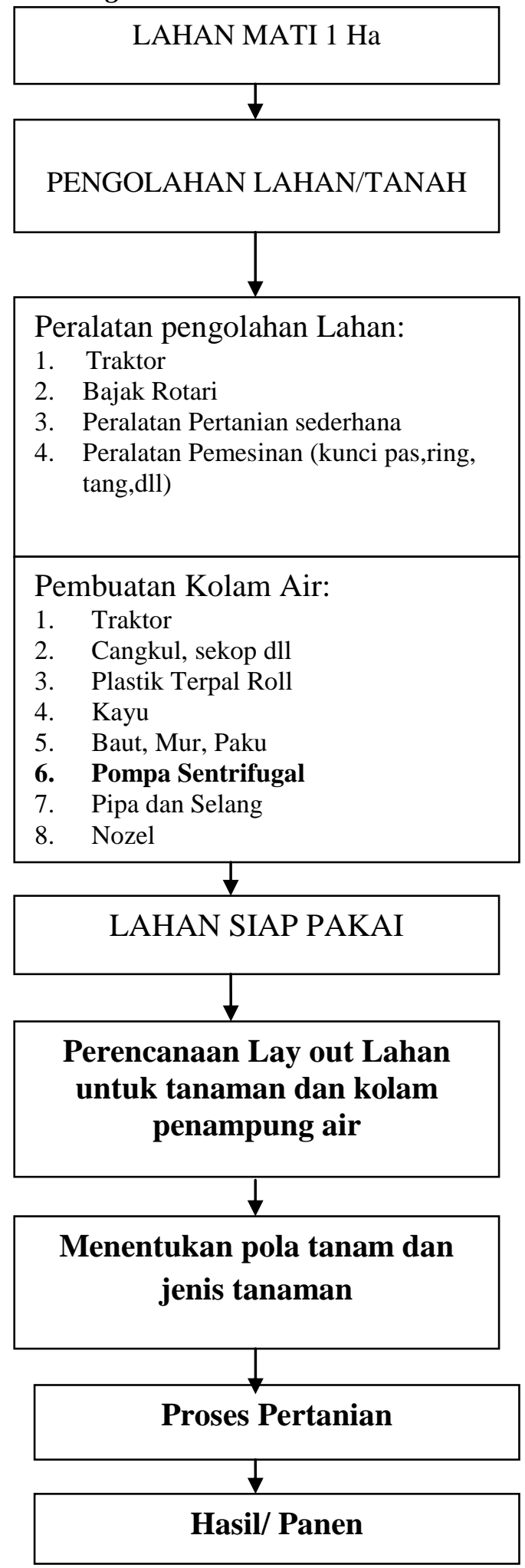

Gambar 3.1 Diagram Alir Penelitian 


\subsection{Lay Out Perencanaan Lahan}

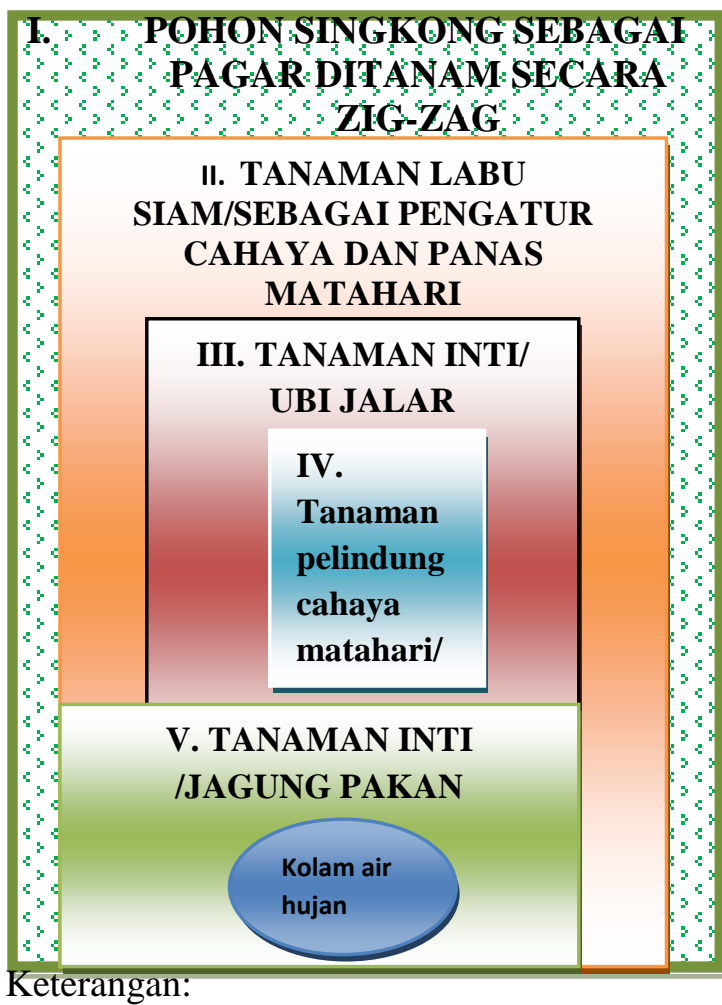

I Adalah tanaman Singkong seluas $1 \mathrm{Ha}$, ditanam secara bersilang (zigzag) diperuntukkan sebagai pagar yang melindungi lahan dari binatang dan sekaligus memberikan nilai tambah.

II Adalah tanaman labu Siam Sebagai pengatur cahaya matahari terhadap tanamaninti dan memberikan nilai tambah

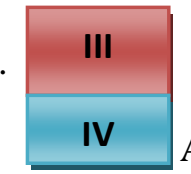

Tanaman Inti Ubi Jalar

AdalahTanaman Pepaya Madu sebagai pengatur panas dan cahaya matahari terhadap tanaman inti dan memberikan nilai tambah

V

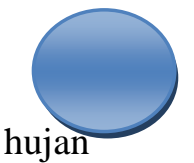

Tanaman Inti/ Jagung Manis

Kolam Penampungan Air
HASIL DAN PEMBAHASAN

4.1.1 Analisis dan Dokumentasi

\subsubsection{Kolam Penampung Air Hujan}

Dalam kegiatan ini setelah proses pengolahan tanah selesai, fokus berikutnya adalah membuat kolam penampung air yang dilakukan dengan cara mengeruk tanah dengan bantuan traktor, cangkul dan sekop. Kolam yang terbentuk dilapis dengan plastik terpal yang tebal dan dibuat berlapis untuk menghindari bocor dan pelapukan oleh cahaya matahari. Ukuran yag dibuat adalah 12 × 6 x $1.8 \mathrm{~m}$. Sehingga mampu untuk menyirami lahan saat tidak ada hujan.

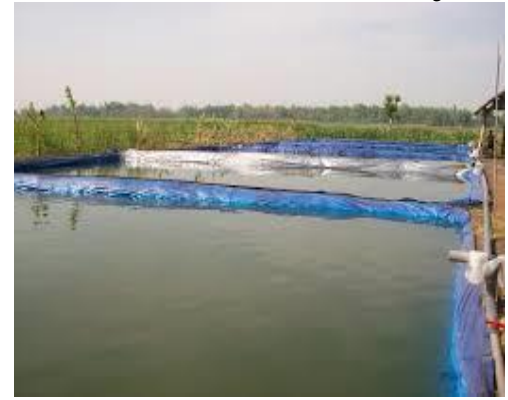

Gambar 4.1 Model kolam penampung air hujan

\subsubsection{Penyiraman Lahan}

Setelah selesai pembuatan kolam penampungan air hujan maka tahap selanjutnya adalah menyiram lahan, itupun dilakukan kalau tidak terjadi hujan, akan tetapi kalau terjadi hujan maka air kolam dapat dimanfaatkan sebagai tempat budidaya ikan untuk member nilai tambah dan mengurangi ongkos dan biaya akomodasi kegiatan sehari-hari.

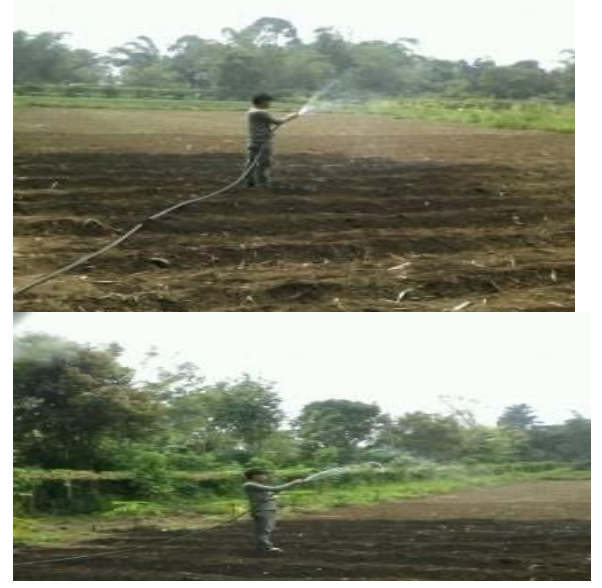




\section{Gambar 4.2 Proses penyiraman lahan dengan bantuan pompa}

\subsubsection{Proses Penanaman}

Dalam Proses penanaman terdiri dari tanaman inti dan tanaman pelindung yang berfungsi sebagai pengatur paparan cahaya matahari terhadap tanaman, dapat dijelaskan sebagai berikut:

\$ Angka I diatas pada lay out berarti tanaman pelindung berupa pohon singkong, ditanam sepanjang empat sisi $\left(400 \mathrm{~m}^{2}\right)$ proses penanaman sangat mudah ditanam secara zigzag yang bertujuan untuk melindungi lahan dari binatang disekitar. Selain sebagai pelindung pohon singkong dapat diambil daunnya $2 \quad x$ seminggu secara bergiliran dan memberikan nilai tambah yang sangat berarti, yang dapat menutupi biaya kebutuhan akomodasi setiap hari. Dan setiap setahun sekali dibongkar untuk diambil singkongnya.

* Angka II adalah tanaman pelindung terhadap tanaman inti dari paparan sinar matahari langsung, artinya matahari sangat penting untuk perkembangan tanaman akan tetapi tidak boleh terpapar secara berlebihan, maka lahan ditanam dengan labu siam yang proses penanaman mudah dan daun yang lebat dapat melindungi tanaman inti dari cahaya yang berlebih, ditanamam sebesar $(3 \times$ x 100) $\mathrm{m}$ sebanyak 3 sisi saja. Tanaman ini banyak diminati karena bibit merupakan bibit unggul dari jepang yang nilai jual sangat tinggi dari bibit lokal. labu ini dipanen $2 x$ dalam seminggu. kalau dikalkulasi setiap bulan hampir 4 ton. Disisi bawah/alas labu siam ditanami dengan tanaman cabe rawit yang tumbuh subur karena terlindung daun labu siam seperti ditanam pada green house.

* Angka III adalah tanaman inti berupa ubi jalar berwarna merah, kuning dan unggu. Komoditi ini ditanam secara organik dan dipanen
$2 \mathrm{x}$ setahun. Ubi jalar ini sangat bagus karena tidak terlalu terpapar matahari langsung dimana terlindung oleh labu siam dan pepaya.

* Angka IV. Adalah tanaman pelindung terhadap tanaman inti berupa pepaya madu, fungsinya sama dengan diatas dan memberikan nilai tambah yang sangat tinggi. Ditanam dan dirawat selama 4 bulan, dan setelah itu sepanjang tahun dapat dipanen setiap minggu minimal $20 \mathrm{~kg} /$ batang, pepaya ini ditanama di tiga sisi setiap jarak 2 meter. Artinya tiap sisi kurang lebih 50 batang dikalikan 3 sisi berarti kira-kira 150 batang. Kalau setiap minggu/batang adalah $20 \mathrm{~kg}$ berarti setiap minggu kira 3 Ton.

* Angka V adalah tanaman inti berupa jagung lokal yang bisa dipakai konsumsi dan jika dibiarkan kering di lahan maka bisa menjadi pakan untuk ayam/ternak. Tanaman ini dipanen $4 \mathrm{x}$ dalam setahun, setiap penanaman hanya sekitar 82 hari.

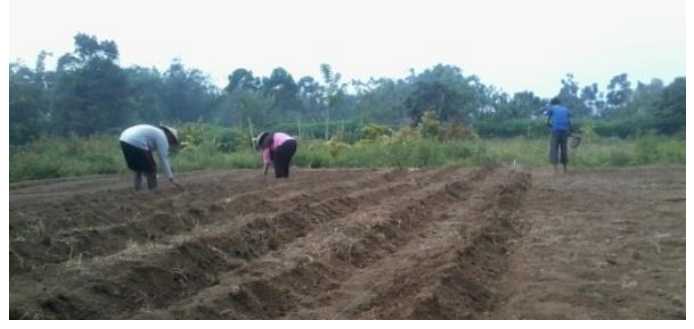

Gambar 4.3 Proses Penanaman Tanaman inti

\subsubsection{Panen}

Proses panen terbagi atas dua kegiatan antara lain:

- Panen Tanaman inti

- Panen tanaman pelindung

\section{Panen Tanaman Inti}

Tanaman inti pada lahan ini adalah ubi jalar dan jagung, dimana ubi jalar dipanen 2 kali dalam setahun sedangkan jagung dapat dipanen 4 kali dalam setahun. Tanaman ubi jalar ini saat panen menggunakan hand traktor dengan bajak tunggal sehingga proses lebih cepat dan bersih, untuk meningkatkan nilai jual maka ubi tersebut dicuci, akan tetapi tonase panen yang berlimpah membuat 
proses pencucian sulit maka kami mencoba membuat alat cuci ubi sederhana yang dijadikan sebagai tugas akhir mahasiswa. Sehingga dari harga jual lepas yang hanya 3000/kg meningkat menjadi 4000-4500/kg dan apabila ditingkatkan dengan mengemas (packaging) menggunakan Koran maka harga bisa mencapai 6000/kg, dan itulah yang kami lakukan.

Untuk tanaman jagung kami tidak mengambil jagung untuk konsumsi manusia tetapi dibiarkan kering dilahan dijual sebagai pakan ayam/ternak. Berawal berawal dari inilah maka kami membuat alat/mesin pemipil jagung yang dijadikan sebagai tugas akhir mahasiwa. Panen jagung 4 kali dalam setahun serta proses pemipilan jagung dapat diproses dengan cepat dan efisien. Sehingga target penanaman 4 kali dalam setahun bisa terlaksana dengan baik.

\section{$>$ Panen Tanaman Pelindung}

Tanaman pelindung adalah labu siam, daun singkong, pepaya madu dan ubi singkong. Tanaman ini kalau dihitung secara keseluruhan lebih bernilai ekonomis dibanding tanaman inti. Karena tanaman ini diambil tiap minggu, sehingga ongkos produksi dan akomodasi sepanjang tahun dapat diambil dari penjualan tanaman ini. Sehingga dalam lahan $1 \mathrm{Ha}$ tersebut dapat memberikan penghasilan yang sangat layak dan banyak. Sebagai contoh daun singkong setiap minggu dapat dijual sebanyak 200 ikat x Rp 2000 maka setiap minggu bisa Rp 400.000, untuk labu setiap minggu bisa dikatakan 1 Ton x Rp 2000 maka bisa menghasilkan 2juta/minggu, untuk pepaya madu sekitar 1-1,5 ton x 2000 maka sekitar 3-4 jt/minggu. Akan tetapi tidak semua tanaman ini kami jual sebab sebagian yang tidak masuk dalam kualitas baik dihancurkan dan dijadikan pupuk organik.

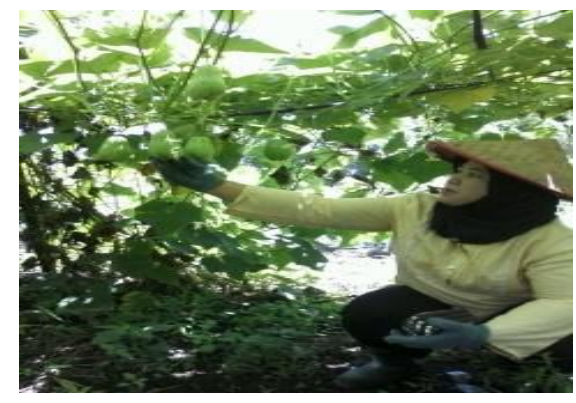

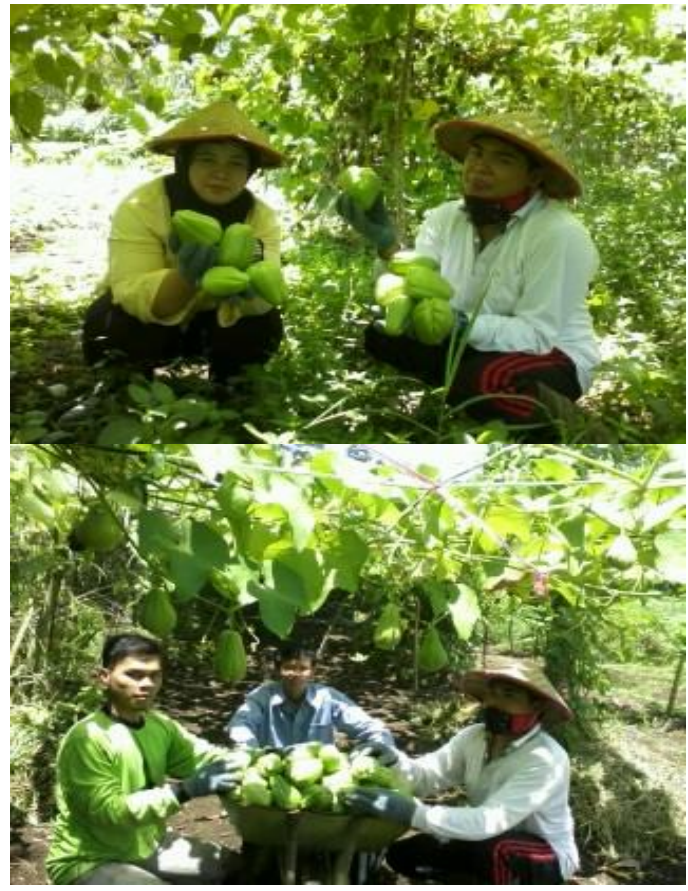

\section{SIMPULAN}

Gambar 4.4 Panen

Didasarkan kepada pemaparan diatas dapat disimpulkan bahwa pentingnya mekanisasi dalam pertanian, hanya dengan sebuah alat/mesin pompa sederhana maka lahan yang selama ini dibiarkan terbengkalai/tandus, dapat diubah menjadi lahan yang produktif dan subur yang bisa dijadikan sebuah mata pencaharian yang bisa dikatakan lebih dari cukup. Dari proses pertanian ini menjadi sebuah terobosan baru untuk menciptakan mesin-mesin baru yang dapat memberikan nilai tambah baik bagi petani maupun bagi teknokrat yang akan menekuni bidang pertanian ini. Sehingga dimasa depan profesi petani merupakan sebuah profesi pilihan yang prestisius. Karena mekanisasi dalam pertanian menjamin terciptanya suasana kerja yang kondusif, efektif dan produktif. Dimasa depan tidak ada lagi alasan bagi petani/kita /mahasiswa untuk membiarkan lahan menjadi lahan tidur, sebab sumber air dapat diambil dari sumberdaya alam tropis berupa hujan yang selama ini tidak dianggap menjadi sebuah komoditi/anugrah yang harus dikumpulkan/ditampung untuk kegiatan pertanian dan perikanan.

Mekanisasi harus membuat kita /mahasiswa menjadi manusia yang innovatif, kreatif, 
produktif dan banyak bersyukur kepada Allah, S.W.T, yang telah menjadikan alam Indonesia khususnya Sumatera Barat menjadi alam yang sangat indah, subur, suhu yang sejuk dan hujan yang ada sepanjang tahun.

Terlaksananya kegiatan inovasi kreativitas mahasiswa ini tidak terlepas dari beberapa pihak yang membantu, untuk itu saya sebagai penulis mengucapkan terima kasih kepada:

1. Bapak Emil, Selaku Pemateri Kuliah Umum dan Pemilik Lahan.

2. Bapak Dekan Fakultas Teknik, Ir. Hariadi, M.Eng yang telah memberi kesempatan, mendukung dan memfasilitasi sebahagian kegiatan ini.

3. Armila, ST. MT selaku KaProdi yang telah mengusahakan kegiatan ini terlaksana dengan baik.

4. Mahasiswa yang terlibat dalam kegiatan ini dan khususnya mahasiswa yang menjadikan kegiatan ini sebagai pengembangan prodi dengan membuat tugas akhir dibidang mesin-mesin pertanian.

\section{DAFTAR PUSTAKA}

Achmad, DR, E.E Ananto dan Astanto evaluasi cara pengolahan tanah dengan traktor media penelitian sukamandi No. 14, 1993, P 1-5

Ali Hamsyah, T 2007, teknologi mekanisasi pertanian pendukung sistem pertanian tanaman pangan industrial, makalah disajikan pada simposium tanaman pangan V di Bogor, tanggal 28-29 2007

Ananto E.Eko, Astanto, Sutrisno \& Ridwan Rahmat 1992 prospect farm mechanization in the density populated area, proceeding of JICA-IPB 5 tahun join seminar as an international conference on engineering application for development of agriculture in the asian and pacific region, Bogor, Indonesia October 1992 Training Centre. JICA.

Koga, Y. 1988. Farm Machinery Vol. II.Tsukuba International Agricultural

Srivasta, A. K, C. E Goering, R. P Rohrbach. 1993. Engneering Principles of Agricultural Machines. ASAE Texbook
Number 6, American Society of Agricultural Engineers.

Setiawan, R. P. A. 2001. Research Report on Development of Variable Rate Granular Applicator for Paddy Field. Laboratory of Agricultural Machinery, Kyoto University.

Esmay, M. I. and Hall, C. W. (eds). 1972. Agricultural Mechanization in Developing Countries, Shin-Norinsha Co. Ltd. 